\title{
OPTIMIZATION OF INGREDIENTS UPON DEVELOPMENT OF THE PROTECTIVE POLYMERIC COMPOSITE COATINGS FOR THE RIVER AND SEA TRANSPORT
}

Andriy Buketov ${ }^{1}$, Serhii Yakushchenko ${ }^{1}$, Abdellah Menou ${ }^{2}$, Oleh Bezbakh ${ }^{1}$, Roman Vrublevskyi ${ }^{1}$, Yaroslava Kalba ${ }^{3}$, Tetyana Cherniavska ${ }^{1}$, Danylo Zhytnyk ${ }^{1}$, Olha Danylyuk ${ }^{3, *}$

${ }^{1}$ Kherson State Maritime Academy, Kherson, Ukraine

${ }^{2}$ International Academy of Civil Aviation, Casablanca, Morocco

${ }^{3}$ Ternopil Volodymyr Hnatiuk National Pedagogical University, Ternopil, Ukraine

*E-mail of corresponding author: laboratory22b@gmail.com

\section{Resume}

It is proved that in order to increase the operational characteristics of parts of the river and sea transport, including their physical and mechanical properties, it is advisable to use the protective polymeric composite coatings.

The effect of fillers on the flexural stresses of the developed epoxy composite was analyzed. The critical content of components was determined by the method of mathematical planning of the experiment: the synthesized powder mixture 0.05 pts.wt., discrete fibers -0.10 to 0.15 pts.wt. per 100 pts.wt. of epoxy oligomer ED-20. Introduction of such ingredients into the epoxy binder allows to increase the flexural stresses to $\sigma_{\mathrm{f}}=77.4 \ldots 78.6 \mathrm{MPa}$. The obtained results allow to create materials with improved values of physical and mechanical properties.

\section{Article info}

Received 5 May 2020

Accepted 10 August 2020

Online 18 December 2020

\section{Keywords:}

composite,

epoxy matrix,

method of mathematical planning

of the experiment,

regression equation

\section{Introduction}

Development of the river and sea transport involves creation of new materials to protect equipment parts from corrosion and wear. Use of the polymer composite materials (PCM) and protective coatings based on them is relevant in this context. Polymer composites are characterized by improved performance, which conditions a wide range of applications in the transport industry to increase the service life of machines and mechanisms [1-2]. It should be noted that nowadays the problem of improving cohesive properties of the known materials is current, which is decisive in analysis of reliability of equipment under critical conditions.

The authors [3-9] have shown that it is advisable to introduce fillers at a critical content in order to improve the properties of coatings, which are operated in the conditions of influence of corrosive environments and variable temperatures, in the complex. At the same time, it is important to choose the additives that should be active to the physical and chemical interaction with the polymer during the crosslinking. It was believed that introduction of fillers in the form of powder and discrete fibers can provide a synergistic effect in improving the material properties. In this context, it is advisable to use the method of mathematical planning of the experiment, which will reduce the number of conducted studies and optimize the content of ingredients to obtain material with the highest parameters of the studied characteristics.

Aim of the investigation - to optimize the content of dispersed and fibrous discrete fillers for the protective coatings of the river and sea transport by the method of mathematical planning of an experiment.

\section{Materials and methods}

The epoxy diane oligomer ED-20 was selected as the main component for the binding when forming epoxy composite materials (CM), which is distinguished by the high adhesive and cohesive strength. For the cross-linking action of epoxy compositions, polyethylene polyamine hardener was used, which allows materials' curing at room temperatures. The PEPA is a low molecular weight substance consisting of monomer units with the following form: [- CH2-CH2-NH- $]_{n}$. A micro-dispersed filler, the synthesized powder mixture (SPM) of the following composition: $\mathrm{Fe}(70 \%)+\mathrm{Ti}(10 \%)+\mathrm{TiC}(15 \%)+\mathrm{Fe}_{3} \mathrm{C}(5 \%)$ and a mixture of discrete fibers (MDF) in the form of fibrous filler: modal (42\%), polyacryl (38\%), polyamide (38\%), were used for experimental studies.

Epoxy CM's forming technology is following [3-5]: 
heating of the resin up to the temperature $\mathrm{T}=(353 \pm 2) \mathrm{K}$ and exposure at this temperature during $\tau=(20 \pm 0.1) \mathrm{min}$; dosage of the filler and its further loading into the epoxy binder; hydrodynamic blending of the oligomer ED-20 and filler during $\tau=(10 \pm 0.1) \mathrm{min}$; ultrasonic processing of the composition during $\tau=(1.5 \pm 0.1) \mathrm{min}$; cooling of the composition to the ambient temperature during $\tau=(60 \pm 5) \mathrm{min}$; introduction of the curing agent PEPA and mechanical blending of the composition during $\tau=(5 \pm 0.1) \mathrm{min}$. Then the curing of the PCM was conducted according to the mode: formation of the specimens and their curing during $\tau=(12.0 \pm 0.1)$ hours at the temperature $\mathrm{T}=(293 \pm 2) \mathrm{K}$; heating with the rate of $v=3 \mathrm{~K} / \mathrm{min}$ to the temperature $\mathrm{T}=(393 \pm 2) \mathrm{K}$; holding of the PCM during $\tau=(2.0 \pm 0.05)$ hours, slowly cooling to the temperature $\mathrm{T}=(293 \pm 2) \mathrm{K}$. To stabilize the structural processes to occur in the CM they were kept during $\tau=24$ hours in the open air at the temperature $\mathrm{T}=(293 \pm 2) \mathrm{K}$ before testing.

The flexural stresses of the PCM were studied in the work according to ASTM D 790 - 03 [10]. To obtain the high performance CMs, after the preliminary experiments, a method of mathematical planning of the experiment was used, which simultaneously allowed to take into account the ratio of components and technological parameters of obtaining composites with a considerable reduction of experimental works [7].

A model of the full factorial experiment $2^{2}$ was used for the design of experiments. The factor levels and variation intervals were selected based on the previous experiments. The root mean square deviation for the coefficients was determined by the formula:

$$
\begin{aligned}
& S\left(a_{i}\right)=\sqrt{S^{2}\left(a_{i}\right)}=\frac{S^{2}(y)}{\sum_{l}^{n} x_{i} l}, \\
& S^{2}(y)=\sum_{l=1}^{N} \sum_{i=1}^{n}\left(Y_{l}-y_{i l}\right)^{2}, \\
& S^{2}(Y)=\frac{S^{2}(y)}{n},
\end{aligned}
$$

where:

$S^{2}(y)$ - dispersions of adequacy;

$S^{2}(Y)$ - average dispersions of adequacy;

$N$ - number of experiments according to the plan;

$n$ - number of parallel experiments;

$x_{i}$ - coded variable.

Significance of the regression coefficients was determined by the Student's test:

$t_{i}=\left|\frac{d_{i}}{S\left(a_{i}\right)}\right|$

where $a_{i}$ - the coefficient value.

The condition of significance of the equation coefficients has the form $t_{i}>t_{p}$, where $t_{p}$ was determined from the table in reference [11] in 5\% significance level. The adequacy of the description of the process of obtaining the CM was tested using the Fisher test:
$F_{i}=\frac{S_{R}^{2}}{S^{2}(y)}$

$S_{R}^{2}=\frac{\sum_{l}^{N} Y_{l}^{2}-\sum_{i}^{N} a_{i} \sum_{l}^{N} x_{i l} y_{l}}{f_{1}}$,

where:

$S_{R}^{2}$ - residual dispersion;

$f_{1}$ - number of degrees of freedom.

The numbers of degrees of freedom $f_{1}$ and $f_{2}$ were determined by the formulas:

$f_{1}=N-(k+1)$,

$f_{2}=N(n-1)$,

where $k$ - the number of the polynomial coefficients.

The table value $F$ of the criterion $F$, taking into account $f_{1}$ and $f_{2}$, was found for the $5 \%$ significance level. Given $F_{i}<F_{p}$, it was considered that the polynomial adequately describes the process under study [12-16].

In order to reduce the error in the study of properties and search for optimal values, five or six parallel measurements were performed and the arithmetic mean was found:

$y=\frac{y_{1}+\ldots+y_{n}}{n}$,

where:

$y_{1}+\ldots+y_{n}$ - results of individual experiments;

$y$ - arithmetic mean of all parallel experiments;

$n$ - number of parallel experiments.

To eliminate false values, the Student's criterion was used [15]:

$\frac{y_{i}-y}{S} \geq t$

where:

$y_{i} \quad$ - the results of a single experiment;

$y$ - the arithmetic mean of all results;

$S$ - quadratic error;

$t \quad$ - the tabular value of the Student test.

The quadratic error was determined by the formula:

$S=\frac{\sqrt{\sum_{l}^{n}\left(y_{i}-y\right)^{2}}}{n}$.

An experiment was considered false if the experimental value of the criterion is greater than the table value: $\left|t_{\text {exp. }}\right| \geq t_{\text {table. }}$.

\section{$3 \quad$ Results}

The flexural stresses, as one of the main properties of composites with different content of micro-dispersed filler and discrete fibers, were investigated in order to optimize the content of ingredients in formation of the 
Table 1 Levels of variables on conditional and natural scale

\begin{tabular}{cccccccc}
\hline \multirow{2}{*}{ components } & factor & $\begin{array}{c}\text { average level, } \\
q,\end{array}$ & $\begin{array}{c}\text { variation step, } \Delta q, \\
\text { pts.wt. }\end{array}$ & \multicolumn{3}{c}{$\begin{array}{c}\text { values of variables (pts.wt.) that } \\
\text { correspond to conditional units }\end{array}$} \\
\cline { 5 - 8 } SPM & $x_{1}$ & 0.10 & 0.05 & -1 & 0.05 & 0.10 & 0.15 \\
MDF & $x_{2}$ & 0.10 & 0.05 & 0.05 & 0.10 & 0.15 \\
\hline
\end{tabular}

Table 2 Scheme of experiment planning

\begin{tabular}{ccccccc}
\hline $\begin{array}{c}\text { no. of } \\
\text { experiment }(\mathrm{u})\end{array}$ & $x_{0}$ & $x_{1}$ & $x_{2}$ & $x_{3}=x_{1}^{2}-d$ & $x_{4}=x_{1}^{4}-d$ & $x_{1} x_{2}$ \\
\hline 1 & 1 & -1 & -1 & 0.33 & 0.33 & +1 \\
2 & 1 & +1 & -1 & 0.33 & 0.33 & -1 \\
3 & 1 & -1 & +1 & 0.33 & 0.33 & -1 \\
4 & 1 & +1 & +1 & 0.33 & -0.33 & +1 \\
5 & 1 & 0 & 0 & -0.67 & -0.67 & 0 \\
6 & 1 & +1 & 0 & 0.33 & -0.67 & 0 \\
7 & 1 & -1 & 0 & 0.33 & 0.33 & 0 \\
8 & 1 & 0 & +1 & -0.67 & 0.33 & 0 \\
9 & 1 & 0 & -1 & -0.67 & 2 & 4 \\
$\sum_{u-1}^{N} x_{i u}^{2}$ & 9 & 6 & 6 & 2 & & 0 \\
\hline
\end{tabular}

Table 3 Results of study of the CM flexural stresses

\begin{tabular}{cccc}
\hline \multirow{2}{*}{ no. of experiment } & \multicolumn{2}{c}{ content of components, $q$, pts.wt. } & flexural stresses during the flexion, $\sigma_{j}$ MPa \\
\cline { 2 - 4 } & $x_{1}$ & $x_{2}$ & $y_{2}$ \\
\hline & 0.05 & 0.05 & 65.4 \\
3 & 0.15 & 0.05 & 63.9 \\
4 & 0.05 & 0.15 & 77.4 \\
5 & 0.15 & 0.15 & 65.6 \\
6 & 0.10 & 0.10 & 70.5 \\
7 & 0.15 & 0.10 & 74.3 \\
8 & 0.05 & 0.10 & 78.6 \\
9 & 0.10 & 0.15 & 69.0 \\
\hline
\end{tabular}

functional layer of the protective coating. It should be noted that as a micro-dispersed filler, the synthesized powder mixture (SPM) of the following composition was used for experimental studies: $\mathrm{Fe}(70 \%)+\mathrm{Ti}(10 \%)+\mathrm{TiC}$ $(15 \%)+\mathrm{Fe}_{3} \mathrm{C}(5 \%)$. A mixture of discrete fibers (MDF) was used in the form of fibrous filler: modal (42\%), polyacryl (38\%), polyamide (38\%). Each component (filler) was coded by units with consideration of the variation step, for standardization and for simplification of calculations (Table 1).

According to the experiment planning scheme nine experiments $(\mathrm{N}=9)$ were conducted, each of which was repeated three times $(p=3)$ in order to exclude system errors (Table 2). In order for the planning matrix to be orthogonal [11], the corrected values of $x^{\prime}$ level were entered, which were calculated by the formula:

$x_{i}^{\prime}=\left(x_{i}\right)^{2}-\frac{\sum_{u-1}^{N} x_{i u}^{2}}{N}$.

The expanded matrix of planning of the complete factor experiment and its results are shown in Table 2. Results of study of the CM flexural stresses are shown in Table 3.

The mathematical model $y=f\left(x_{1}, x_{2}\right)$ was formed as a regression equation [12]:

$y=b_{0}+b_{1} x_{1}+b_{2} x_{2}+b_{11} x_{1}^{2}+b_{22} x_{2}^{2}+b_{12} x_{1} x_{2}$.

The regression coefficients were determined by the 
Table 4 The coefficients of regression equation

\begin{tabular}{cccccc}
\hline $\mathrm{b}_{0}$ & $\mathrm{~b}_{1}$ & $\mathrm{~b}_{2}$ & $\mathrm{~b}_{11}$ & $\mathrm{~b}_{22}$ & $\mathrm{~b}_{12}$ \\
\hline 74.33 & -2.93 & 1.70 & 0.20 & -5.50 & -2.58 \\
\hline
\end{tabular}

Table 5 Values of dispersions of adequacy $\left(S_{u i}^{2}\right)$ and the mean square error $\left(\sigma^{2}\{y\}_{i}\right)$

\begin{tabular}{|c|c|c|c|c|}
\hline \multirow{2}{*}{ no. } & \multicolumn{2}{|c|}{ the dispersions of adequacy } & \multicolumn{2}{|c|}{ the mean square error } \\
\hline & conditional designation & value & conditional designation & value \\
\hline 1 & $S_{u 1}^{2}$ & 4.020 & $\sigma^{2}\{y\}_{1}$ & 2.010 \\
\hline 2 & $S_{u 2}^{2}$ & 5.180 & $\sigma^{2}\{y\}_{2}$ & 2.590 \\
\hline 3 & $S_{u 3}^{2}$ & 4.940 & $\sigma^{2}\{y\}_{3}$ & 2.470 \\
\hline 4 & $S_{u 4}^{2}$ & 2.240 & $\sigma^{2}\{y\}_{4}$ & 1.120 \\
\hline 5 & $S_{u 5}^{2}$ & 1.220 & $\sigma^{2}\{y\}_{5}$ & 0.610 \\
\hline 6 & $S_{u 6}^{2}$ & 1.500 & $\sigma^{2}\{y\}_{6}$ & 0.750 \\
\hline 7 & $S_{u 7}^{2}$ & 3.860 & $\sigma^{2}\{y\}_{7}$ & 1.930 \\
\hline 8 & $S_{u 8}^{2}$ & 1.680 & $\sigma^{2}\{y\}_{8}$ & 0.840 \\
\hline 9 & $S_{u 9}^{2}$ & 1.820 & $\sigma^{2}\{y\}_{9}$ & 0.910 \\
\hline
\end{tabular}

formula [13]:

$$
b_{i}=\frac{\sum_{u=1}^{N} x_{i} y_{i}}{\sum_{u=1}^{N} x_{i u}^{2}} .
$$

Received coefficients of the regression equation are given in Table 4.

As a result, in the analysis of flexural stresses, the following regression equation was determined:

$$
\begin{aligned}
y= & 74.33-2.93 x_{1}+1.70 x_{2}+0.20 x_{1}^{2}- \\
& -5.50 x_{2}^{2}-2.58 x_{1} x_{2}
\end{aligned}
$$

For the statistical processing of experiment results, a test of reproducibility of experiments by the Cochran test, was conducted:

$$
G=\frac{S_{u \max }^{2}}{\sum_{u=1}^{N} S_{u}^{2}} \leq G_{\left(0,05 ; f_{1} ; f_{2}\right)}
$$

where:

$S_{u i}^{2}$ - dispersion of experiment results on combinations of a few factor levels for $\mathrm{m}=3$;

$m$ - number of parallel experiments;

$S_{u \text { max }}^{2}$ - the highest dispersion in design line.

Dispersions of adequacy were determined by the formula:

$$
S_{u i}^{2}=\frac{\sum_{i=1}^{m}\left(y_{i}-\overline{y_{i}}\right)^{2}}{m-1},
$$

where:

$y_{i m}$ - value, received from each parallel experiment;

$\overline{y_{i}}$ - average value $y$, received in parallel experiments.

The mean square error was determined as:

$$
\sigma^{2}\{y\}=\frac{\sum_{i=1}^{N=9} \sigma^{2}\{y\}_{i}}{N(m-1)}
$$

where: $\sigma^{2}\{y\}_{i}=\sum_{i=1}^{m=3}\left(y-\overline{y_{i}}\right)^{2}$

$\sigma^{2}\left\{y_{a v}\right\}=\frac{a^{2}\{y\}}{N}$, or $S_{b 0}^{2}=\frac{S_{0}^{2}}{N}$.

Dispersion values are shown in Table 5.

Moreover:

$\sum_{i=1}^{N} S_{u i}^{2}=13.23, \sigma^{2}\{y\}=S_{0}^{2}=1.470$.

Then, the calculated value of the Cochran test at the $5 \%$ level of significance [14]:

$G_{\text {calc }}=\frac{S_{u_{\max }}^{2}}{\sum_{i=1}^{N} S_{u i}^{2}}$,

$G_{\text {calc }}=\frac{2.59}{13.23}=0.196$.

Testing the experiment results by the Cochran test [14-15] for a fixed probability $\alpha=0.05$ confirmed the reproducibility of the experiments. Dispersion of experiment results on combinations of a few factor levels: $S_{u \max }^{2}=0.196$. Calculated value of the Cochran test is $G_{\text {calc }}=0.196$.

Table value of the Cochran test is $G_{t a b}=0.478$.

That is, Equation (20) is satisfied:

$$
G_{\text {calc }}=0196 \leq G_{t a b}=0.478 \text {. }
$$

Subsequently, the coefficients significance of regression 
Table 6 The experimental results of study of flexural stresses of materials

\begin{tabular}{|c|c|c|c|c|}
\hline \multirow[t]{2}{*}{ no. of experiment } & \multicolumn{3}{|c|}{$\begin{array}{c}\text { flexural stresses, } \\
\sigma_{f}, \mathrm{MPa}\end{array}$} & \multirow{2}{*}{$\begin{array}{c}\text { average value, } \\
\sigma_{f}, \mathrm{MPa}\end{array}$} \\
\hline & 1 & 2 & 3 & \\
\hline 1 & 63.8 & 66.5 & 65.9 & 65.4 \\
\hline 2 & 62.1 & 64.4 & 65.2 & 63.9 \\
\hline 3 & 76.0 & 77.1 & 79.1 & 77.4 \\
\hline 4 & 65.2 & 64.8 & 66.8 & 65.6 \\
\hline 5 & 70.0 & 70.1 & 71.4 & 70.5 \\
\hline 6 & 73.8 & 75.3 & 73.8 & 74.3 \\
\hline 7 & 77.9 & 77.7 & 80.2 & 78.6 \\
\hline 8 & 68.0 & 69.8 & 69.2 & 69.0 \\
\hline 9 & 71.4 & 73.1 & 73.0 & 72.5 \\
\hline
\end{tabular}

Table 7 Dispersion of coefficients of regression $\left(S_{b}^{2}\right)$ and calculated values of the Student's criterion $\left(t_{\text {cale }}\right)$

\begin{tabular}{|c|c|c|c|c|}
\hline \multirow{2}{*}{ no. } & \multicolumn{2}{|c|}{ dispersion of coefficients of regression } & \multicolumn{2}{|c|}{ calculated values of the Student's criterion } \\
\hline & conditional designation & value & conditional designation & value \\
\hline 1 & $S_{b 0}^{2}$ & 0.163 & $t_{0 p}$ & 179.49 \\
\hline 2 & $S_{b_{1}}^{2}$ & 0.245 & $t_{1 p}$ & 5.93 \\
\hline 3 & $S_{b 2}^{2}$ & 0.245 & $t_{2 p}$ & 3.43 \\
\hline 4 & $S_{b_{11}}^{2}$ & 0.735 & $t_{11 p}$ & 0.23 \\
\hline 5 & $S_{b 22}^{2}$ & 0.735 & $t_{22 p}$ & 6.42 \\
\hline 6 & $S_{b 12}^{2}$ & 0.368 & $t_{12 p}$ & 4.2 \\
\hline
\end{tabular}

equation was determined by analyzing the results according to the experimental design (Table 6).

Then, the dispersions of the regression coefficients (Table 7) were determined by:

$S_{b i}^{2}=\frac{S_{0}^{2}}{\sum_{u-1}^{N} x_{i u}^{2}}$.

The significance of the regression coefficients was determined by the Student's test [16]. Here with the table $\left(t_{T}\right)$ and calculated criterion $\left(t_{\text {calc }}\right)$ of the Student's test (Table 7) were determined.

Depending on freeness: $f=\mathrm{N}(\mathrm{n}-1)=9(3-1)=18$, the Student's test value was calculated, which is $t_{\mathrm{T}}=2.1$.

Calculated values of the Student's test $\left(t_{\text {calc }}\right)$ and coefficients significance were determined: $t_{0}, t_{1}, t_{2}, t_{11}, t_{22}, t_{12}>t_{\mathrm{T}}$ Moreover:

$t_{i}=\frac{\left|b_{i}\right|}{S_{b_{i}}}$.

Calculated values of the Student's criterion $t_{0 p}, t_{1 p}$, $t_{2 p}, t_{12 p}, t_{22 p}$ are larger than $t_{T}$, so it was considered that $b_{0}, b_{1}, b_{2}, b_{12}, b_{22}$ coefficients of the regression equation are significant. Calculated values $t_{11 p}$ is lower than $t_{T}$, so it was considered that $b_{11 p}$ coefficient of the regression equation is insignificant. As a result of rejection of the insignificant coefficients, the following regression equation was received:

$y=74.33-2.93 x_{1}+1.70 x_{2}-5.50 x_{2}^{2}-2.58 x_{1} x_{2}$.

The adequacy of the model was checked by the Fisher test [17]:

$F_{c}=\frac{S_{u \max }^{2}}{S_{y}^{2}} \leq F_{\left(0.05 ; f a d ; f_{y}\right)}$,

where $S_{u \max }^{2}=2.59$ - calculated value of dispersion of adequacy (Table 5),

$S_{y}^{2}=\frac{\sum_{i=1}^{N} S_{u i}^{2}}{N}$,

$S_{y}^{2}=1.470$ - mean square error,

So: $F_{c}=0.415$,

$F_{\left(0.05: f_{a d} ; f_{u}\right)}$ - table value of the Fisher test in $5 \%$ significance level $\left(f_{1}=\mathrm{N}-(k+1)=9-(5+1)=3\right.$, $\left.f_{2}=\mathrm{N}(\mathrm{n}-1)=9(3-1)=18\right)$. So: $F_{(t)}=3.16$ [18].

Calculated value of Fisher test is less than the table one, so Equation (21) is satisfied. It is possible to assume that equation adequately characterizes the composition.

Interpretation process of the obtained mathematical model, as a rule, is not just determination of factors influence. A simple comparison of absolute value of linear coefficients does not determine the relative degree factors 

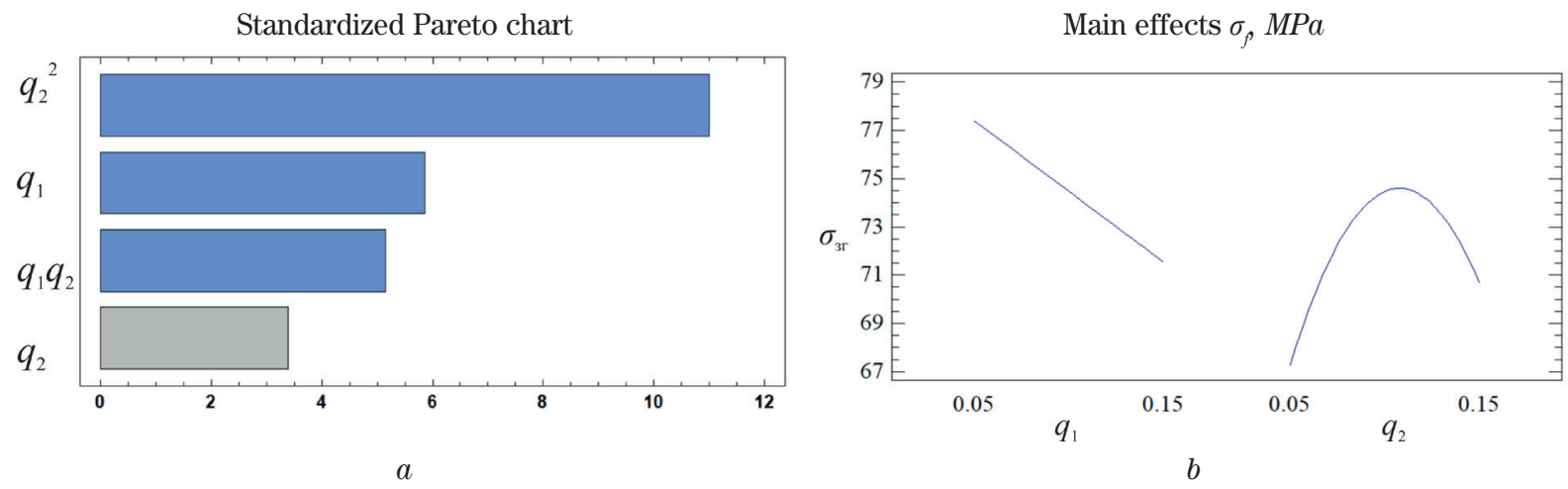

Figure 1 Standardized Pareto chart (a) and main effects (b)

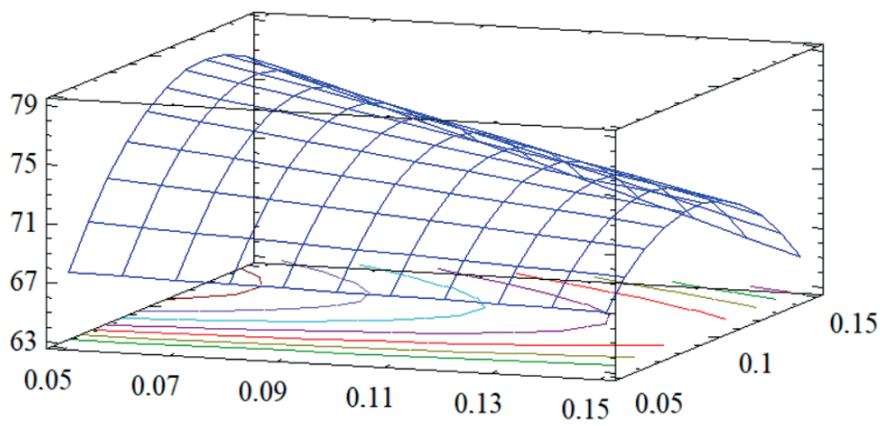

Figure 2 Estimated surface $\sigma_{f}=f\left(q_{1}, q_{2}\right)$

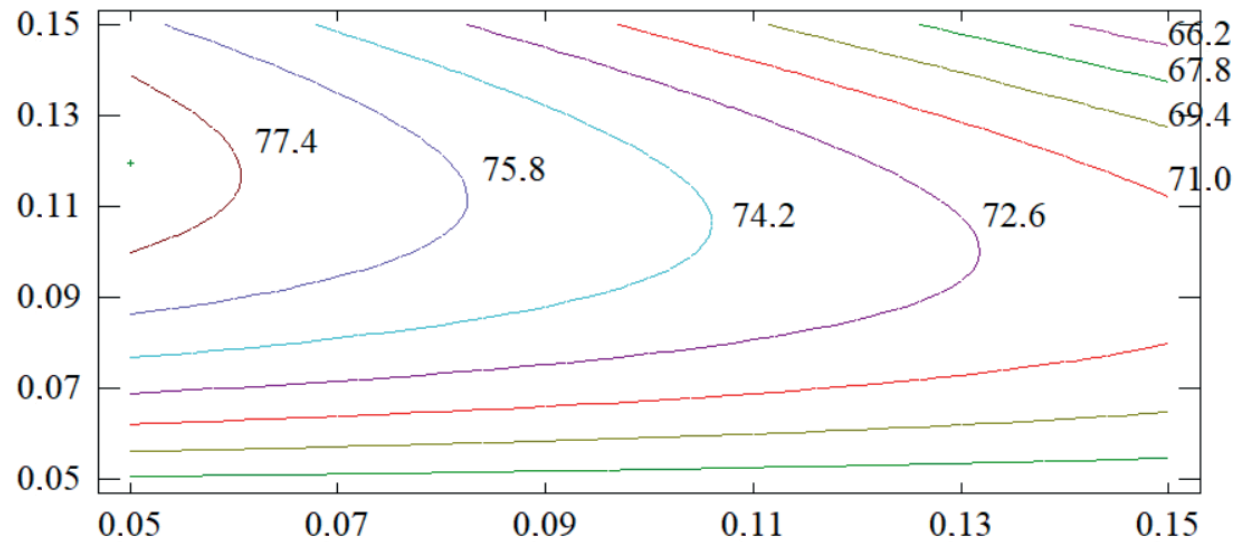

Figure 3 Contours of estimated response surface, which illustrate dependence of the flexural stresses on the content of the two fillers in the complex

influence, since there are also quadratic squared terms and paired interactions. In a detailed analysis of the obtained adequate model, it is necessary to take into account the fact that for a quadratic model the degree of factor influence on the change of output value is not constant.

\section{Discussion}

Dependencies that connect normalized and natural values of the variables are as follows:

$x_{i}=\frac{q_{i}-q_{i 0}}{\Delta q_{i}}$,

where:

$q_{i} \quad$ - value of $i$ experiment factor, $q_{i 0}$ - value of zero level,

$\Delta q_{i}$ - variation interval.

Substituting these values in accordance with Equation (26) into the regression equation and transforming it, one obtains the following regression equation with the natural values of the variables:

$$
\begin{aligned}
\sigma_{f}= & 44.63+44.33 q_{1}+577.0 q_{2}- \\
& -1030.0 q_{1} q_{2}-2200.0 q_{2}^{2}
\end{aligned}
$$

Given equation in natural values allows only predicting the output value for any point in the middle of the range of factor variations. However, with its help it is possible to construct graphs of dependence of the output value (flexural stresses) from any factor (or two factors). Geometric interpretation of the response surface is shown in Figures 1-3. 
Based on the experimental studies, it has been found that both factors are significant. It should be noted that effect of content of the SPM on values of the flexural stresses is higher compared to the MDF (according to the Pareto chart). It was determined that the optimal values of the flexural stresses have a developed epoxy composite with the SPM and the MDF at the following contents: the SPM is 0.05 pts.wt., MDF -0.10 to 0.15 pts.wt. $\left(\sigma_{\mathrm{f}}=77.4\right.$ to $\left.78.6 \mathrm{MPa}\right)$ by analyzing the calculated response surface.

The obtained results indicate that both factors of the regression equation are significant. It should be noted that the greatest influence on the output parameters of the composite have a quadratic dependence of the first factor and linear dependence of the second factor. In the course of the analysis, it was found that values of the flexural stresses have the maximal values at the optimal content of components. In particular, from Figure 2 it is noticeable that an additional increase in the flexural stresses is possible when the content of the SPD filler is increased.

The developed PCMs will be used for the repair of equipment, mechanisms and systems of a marine vessel [19], such as:
- pipeline systems characterized by the corrosion damage;

- deck mechanisms (cargo devices).

\section{Conclusions}

The critical content of the dispersive and fiber fillers: the synthesized powder mixture is 0.05 pts.wt., the mixture of discrete fibers -0.10 to 0.15 pts.wt. per 100 pts.wt. of epoxy oligomer ED-20 was found by the method of mathematical planning of the experiment. Introduction of such ingredients into the epoxy binder allows to increase the flexural stresses of the epoxy composites from $\sigma_{\mathrm{f}}=48.0$ $\mathrm{MPa}$ (for epoxy matrix) to $\sigma_{\mathrm{f}}=77.4$ to $.78 .6 \mathrm{MPa}$.

It was analyzed that with increasing the content of the synthesized powder mixture it is possible to increase values of the flexural stresses. These studies will be presented in the future works. The obtained results allow to create materials with improved physical and mechanical properties in the complex. The obtained materials can be used as the protective coatings to increase the performance and for repairing of the vehicle parts.

\section{References}

[1] FRIEDRICH, K. Polymer composites for tribological applications. Advanced Industrial and Engineering Polymer Research [online]. 2018, 1(1), p. 3-39. ISSN 2542-5048. Available from: https://doi.org/10.1016/j.aiepr.2018.05.001

[2] GUZANOVA, A., BREZINOVA, J., DRAGANOVSKA, D., MARUSCHAK, P. O. Properties of coatings created by HVOF technology using micro-and nano-sized powder. Koroze a Ochrana Materialu [online]. 2019, 63, p. 86-93. eISSN 18041213. Available from: https://doi.org/10.2478/kom-2019-0011

[3] BUKetov, A. V., SAPRONOV, O. O., BRAIlO, M. V., MARUSCHAK, P. O., YAKUSHChENKO, S. V., PANIN, S. V., NIGALATIY, V. D. Dynamics of destruction of epoxy composites filled with ultra-dispersed diamond under impact conditions. Mechanics of Advanced Materials and Structures [online]. 2020, 27(9), p. 725-733. ISSN 1537-649, eISSN 1537-6532. Available from: https://doi.org/10.1080/15376494.2018.1495788

[4] STUkhlyak, P. D., Buketov, A. V., PANin, S. V., MARuschaK, P. O., MOROZ, K. M., POLTARAnin, M. A., VUKHERER, T., KORNIENKO, L. A., LYUKSHIN, B. A. Structural fracture scales in shock-loaded epoxy composites. Physical Mesomechanics [online]. 2015, 18, p. 58-74. ISSN 1029-9599, eISSN 1990-5424. Available from: https://doi. org/10.1134/S1029959915010075

[5] BUKETOV, A. V., BRAILO, M. V., STUKHLYAK, D. P., YAKUSHCHENKO, S. V., SAPRONOV, O. O., CHERNIAVSKYI, V. V., HUSIEV, V. M., DMITRIEV, D. A., YATSYUK, V. M., BEZBAKH, O. M., NEGRUTSA, R. Y. Optimization of components in development of polymeric coatings for restoration of transport vehicles. Bulletin of the Karaganda University. Mathematics Series [online]. 2018, 92(4), p. 119-131. ISSN 2518-7929, eISSN 2663-5011. Available from: https://doi. org/10.31489/2018M4/119-131

[6] ZHANG, L., ZHANG, G., CHANG, L., WETZEL, B., JIM, B., WANG, Q. Distinct tribological mechanisms of silica nanoparticles in epoxy composites reinforced with carbon nanotubes, carbon fibers and glass fibers. Tribology International [online]. 2016, 104, p. 225-236. ISSN 0301-679X. Available from: https://doi.org/10.1016/j. triboint.2016.09.001

[7] BUKETOV, A. V., STUKHLYAK, P. D., KALBA, E. M. Physicochemical processes in the formation of epoxy composite materials (in Ukrainian). Ternopil: Zbruch, 2005.

[8] MARINI, M., RIVALTA, E., MOLENDI, P., DI SILVESTRI, P., BONACINI, C. Mechanical analysis of structural adhesive for marine joints. Journal of Adhesion Science and Technology [online]. 2013, 27, p. 820-824. ISSN 0169-4243, eISSN 1568-5616. Available from: https://doi.org/10.1080/01694243.2012.727152

[9] DAS, G., BISWAS, S. Physical, mechanical and water absorption behaviour of coir fiber reinforced epoxy composites filled with $\mathrm{Al}_{2} \mathrm{O}_{3}$ particulates. IOP Conference Series: Materials Science and Engineering [online]. 2016, 115, 012012. ISSN 1757-8981, eISSN 1757-899X. Available from: https://doi.org/10.1088/1757-899X/115/1/012012 
[10] ASTM D790-03. Standard Test methods for flexural properties of unreinforced and reinforced plastics and electrical insulating materials [online]. Available from: https://www.astm.org/database.cart/historical/D790-03.htm.

[11] BRAILO, M. V., BEZBAKH, O. M., HUSIEV, V. M., YAKUSHCHENKO, S. V. Modified epoxy matrix with improved properties for protection of transport vehicles. Bulletin of the Karaganda University. Mathematics series. 2019, 95(3), p. 88-100. ISSN 2518-7929, eISSN 2663-5011.

[12] ASGHAR, A., RAMAN, A., AZIZ, A., DAUD, W. M. A. W. A comparison of central composite design and Taguchi method for optimizing Fenton process. The Scientific World Journal [online]. 2014, 2014, 869120. ISSN 2356-6140, eISSN 1537744X. Available from: https://doi.org/10.1155/2014/869120

[13] RAJMOHAN, T., PALANIKUMAR, K. Application of the central composite design in optimization of machining parameters in drilling hybrid metal matrix composites. Measurement [online]. 2013, 46(4), p. 1470-1481. ISSN 02632241. Available from: https://doi.org/10.1016/j.measurement.2012.11.034

[14] WILRICH, P. T. Critical values of Mandel's $\mathrm{h}$ and k, the Grubbs and the Cochran test statistic. AStA Advances in Statistical Analysis [online]. 2013, 97(1), p. 1-10. ISSN 1863-8171, eISSN 1863-818X. Available from: https://doi. org/10.1007/s10182-011-0185-y

[15] BAXEVANAKIS, C., JEULIN, D., VALENTIN, D. Fracture statistics of single-fibre composite specimens. Composites Science and Technology [online]. 1993, 48(1-4), p. 47-56. ISSN 0266-3538. Available from: https://doi.org/10.1016/02663538(93)90119-2

[16] BALESCU, R. C. Equilibrium and non-equilibrium statistical mechanics. John Wiley \& Sons, 1975. ISBN 9780471046004.

[17] KIM, H. Y. Statistical notes for clinical researchers: chi-squared test and Fisher's exact test. Restorative Dentistry and Endodontics [online]. 2017, 42(2), p. 152-155. ISSN 2234-7658, eISSN 2234-7666. Available from: https://doi.org/10.5395/ rde.2017.42.2.152

[18] COHEN, J. Statistical power and analysis for the behavioral sciences. 2nd ed. Hisdale, NJ: Lawrence Erlbaum Associates;1988, p. 79-8.

[19] BUKETOV, A., MARUSCHAK, P., SAPRONOV, O., ZINCHENKO, D., YATSYUK, V., PANIN, S. Enhancing performance characteristics of equipment of sea and river transport by using epoxy composites. Transport [online]. 2016, 31(3), p. 333-342. ISSN 1648-4142, eISSN 1648-3480. Available from: https://doi.org/10.3846/16484142.2016.1212267 